\title{
Catalytic effect of praseodymium oxide additive on the microstructure and electrical property of graphite anode
}

Rongyan Wang ${ }^{\mathrm{a}}$, Guimin Lu ${ }^{\mathrm{a}, *}$, Wenming Qiao ${ }^{\mathrm{b}}$, Ze Sun ${ }^{\mathrm{a}}$, Haizheng Zhuanga

$$
\text { Jianguo } \mathrm{Yu}^{\mathrm{a}, \mathrm{b}}
$$

a) National Engineering Research Center for Integrated Utilization of Salt Lake Resources,

East China University of Science and Technology, Shanghai, 200237, P. R. China;

b) State Key Laboratory of Chemical Engineering, East China University of Science and Technology, Shanghai, 200237, P. R. China;

${ }^{*}$ Corresponding author. Tel: +86 21 6425-2065; Fax: +86 2164252826.

E-mail: gmlu@ecust.edu.cn (G. M. Lu ) 


\begin{abstract}
Based on the revealed interactions (dissociation energy) between several typical metals (transition and rare-earth elements) and carbon atoms through the DFT quantum mechanics method, Pr can be predicted to possibly be a new potential catalyst. Indeed, Praseodymium oxide $\left(\operatorname{Pr}_{6} \mathrm{O}_{11}\right)$ was insightfully found to catalyze the graphitization more efficiently than the other selected additives. The effects of $\operatorname{Pr}_{6} \mathrm{O}_{11}$ catalyst on the microstructure of the graphite anode were investigated by XRD, Raman spectroscopy, SEM, and TEM. The results indicate that $\operatorname{Pr}_{6} \mathrm{O}_{11}$ addition remarkably improves the formation of crystallites, thereby largely enhancing the electrical property of graphite anode. The graphite anode with a low electrical resistivity of $5.0 \mu \Omega \cdot \mathrm{m}$ was successfully available by adding 3 wt. $\% \operatorname{Pr}_{6} \mathrm{O}_{11}$ at $2800{ }^{\circ} \mathrm{C}$. Finally, the catalytic graphitization mechanism of rare-earth element was proposed based on the experimental results.
\end{abstract}




\section{Introduction}

Graphite anode offers a wide range of useful properties pertaining to lightweight, low electrical resistivity, and high thermal stability, making it a very interesting material to aluminum and magnesium electrolysis [1]. These properties are affected by the important process - graphitization, which is the transformation of the disordered carbon materials into three-dimensional graphite under high heat-treatment temperature (HTT) [2]. In the last few decades, the catalytic graphitization of carbon materials was reported using such elements as silicon, boron, titanium, nickel, and manganese [3-9].

Recently, some complex methods were proposed to improve the properties of carbon materials. For instance, catalytic graphitization under magnetic field, through chemical activation, or even under focused electron beam irradiation without any heat treatment [10-12]. For industrial scale application, the above combinations to produce carbon materials are still difficult. Therefore, it attracts much attention to improving properties of materials through adding low amount of catalyst without extra treatment. A significant effect of catalysis was observed when catalyst content was more than 10 wt. $\%[10,13]$. The rare-earth elements appear to meet the rigorous requirement to catalyze the graphitization of carbon materials. Yi et al. reported that the yttrium content of 4 wt. \% significantly catalyzed the graphitization of non-graphitizable furan resin based carbon [14], and Zhang et al. found that lanthanum oxide with a low content of 5 wt. \% obviously improved the properties of $\mathrm{C} / \mathrm{C}$ composites [15]. This phenomenon is in accordance with the case of rare-earth element in alloy with a low content (0.2-2.0 at. \%), demonstrating that a slight adding amount of rare-earth element improved the properties of material [16].

About the catalytic graphitization, two questions still need to be addressed: (1) 
Why do some metals provide significantly higher catalytic activity than others? (2) What is the selection mechanism of the efficient catalysts to improve the properties of carbon materials? To answer these questions, some researches focused on the interactions between metal and carbon atoms, which can be divided into the theoretical study of metal cluster and construction of potential function to describe the interactions. For metal carbide clusters, almost all transition metals were studied in different isomers for their $\mathrm{MC}_{\mathrm{n}}(\mathrm{n}=1-12)[17,18]$. For the potential function, several bond-order potentials were proposed and constructed to describe the interactions of different metals and carbon atoms, such as improved Brenner-type potential [19], reactive force field potential (ReaxFF) [20, 21], and the analytical bond order potential [22]. All the parameters of these potential functions were based on the density functional theory (DFT) training set, and therefore, these potential functions were proved suitable to accurately simulate the molecular dynamics of carbon materials pyrolysis [23].

In this study, based on the DFT quantum mechanics (QM) method of parameterizing the potential during construction progress, the interactions between several typical metals (transition and rare-earth elements) and carbon atoms were calculated to find efficient catalysts to improve the properties of carbon materials. Praseodymium oxide $\left(\mathrm{Pr}_{6} \mathrm{O}_{11}\right)$ was discovered to catalyze the graphitization of graphite anode based on the comparison of DFT results. Further, the effects of the HTT and $\operatorname{Pr}_{6} \mathrm{O}_{11}$ adding content on the properties of graphite anode were investigated. Finally, the catalytic graphitization mechanism of rare-earth element was proposed.

\section{Experimental}

\subsection{Computational method}

Calculation was performed according to the method proposed by Nielson [21]. All 
the metal-hydrocarbon QM calculations were performed using the hybrid DFT functional B3LYP as implemented by the $\mathrm{Dmol}^{3}$ module of Materials Studio 6.1. This DFT functional uses the Becke 3-parameter functional [24] (B3) combined with the correlation functional of Lee, Yang, and Par [25] (LYP), and is well known to produce good descriptions of reaction profiles for the transition-metal containing compounds [21]. Double numerical plus polarization (DNP) function was used in calculations. The threshold values of the convergence criteria for energy, gradient, displacement convergence, and self-consistent field (SCF) density convergence were $1 \times 10^{-6} \mathrm{Ha}$, $0.002 \mathrm{Ha} / \AA ̊ \cap, 0.005 \mathrm{Ha} / \AA$, and $1 \times 10^{-6} \mathrm{Ha}$, respectively. A small electron thermal smearing value of $0.005 \mathrm{Ha}$ was used in the calculations to speed up the SCF convergence efficiency during the optimization.

\subsection{Preparation of graphite anode}

Coal-based needle coke and coal tar pitch were used as aggregate and binder (the detailed sources and basic properties were depicted in Supplementary Table S1), and additives such as $\operatorname{Pr}_{6} \mathrm{O}_{11}, \mathrm{Ti}, \mathrm{Fe}_{2} \mathrm{O}_{3}, \mathrm{La}_{2} \mathrm{O}_{3}$, and $\mathrm{CeO}_{2}$ powders were screened with a powder size $<76 \mu \mathrm{m}$. Coal-based needle coke (the size distribution according to our previous report [15]), coal tar pitch (23 wt. \%), and $\operatorname{Pr}_{6} \mathrm{O}_{11}$ powder (0-5 wt. \%) were mixed at $155^{\circ} \mathrm{C}$, and then hot-molded at $135^{\circ} \mathrm{C}$ under a pressure of $23.6 \mathrm{MPa}$. Then, the samples with the size of $120 \mathrm{~mm} \times 60 \mathrm{~mm} \times 20 \mathrm{~mm}$ were treated following the typical procedure, including baking, two cycles of coal tar pitch impregnation/carbonization, and finally graphitization at $2800{ }^{\circ} \mathrm{C}$ [15]. Besides, to understand the effects of $\operatorname{Pr}_{6} \mathrm{O}_{11}$ on the properties of the resultant graphite anode better, the samples with the addition of other metals or metallic oxides were prepared through the same steps to compare the effects. The samples were labeled as GA-XY (GA is the graphite anode, $\mathrm{X}$ is the 
abbreviation of additive, and $\mathrm{Y}$ is the content of additive).

\subsection{Characterization}

The crystalline structures of graphite anode were characterized by XRD (Rigaku $\mathrm{D} / \mathrm{max}-2550 \mathrm{VB}+/ \mathrm{PC}$ diffractometer using $\mathrm{Cu} \mathrm{K} \alpha$ radiation). The standardized XRD measurement of lattice parameters and crystalline size of graphite anode was carried out (Detailed XRD measurement was depicted in Supplementary) [26]. The crystalline size along c-axis $\left(L_{c}\right)$ and a-axis $\left(L_{a}\right)$ of graphite anode was respectively calculated from the (002) and (110) reflection by two methods to guarantee the reasonable value. The first method to calculate the crystalline size is based on Scherrer' s formula (1),

$$
L=K \lambda / \beta \cos \theta
$$

where $\lambda$ is the wave length of $X$-ray $(0.154056 \mathrm{~nm}), \theta$ is the position of the peak, $\beta$ is the full width at half maximum intensity (FWHM) in $2 \theta$ (rad) units, and $K$ is the shape factor depending on the reflection plane $(0.89$ for 002 peak in $L_{c}$ calculations and 1.84 for 110 peak in $L_{a}$ calculations) [27]. Here, $\beta$ is determined from equation (2),

$$
\beta=B-b
$$

where $B$ and $b$ are the measured FWHM for the carbon and the silicon standard, respectively.

The second method is originally derived by Scherrer' s equation, and improved by Alexander $[26,28]$. Nonetheless, the shape factor $K$ is set

to be one in the reference [26]. For the (002) and (110) reflection, the 
domain size is calculated as:

$$
\begin{aligned}
& L_{c}(002)=9.1 / \beta \\
& L_{a}(110)=11.3 / \beta
\end{aligned}
$$

$\beta / B=0.9981266-0.0681532 v-2.592769 v^{2}+2.621163 v^{3}-0.9584715 v^{4}(5)$ where $v$ is defined as $b / B$.

The degree of graphitization ( $g$ ) was estimated by the Mering-Maire formula (6). The (002) peak position of graphite anode was calibrated using Si standard with a slow scan rate of $0.02^{\circ} / 3 \mathrm{~s}$.

$$
g=\left(0.3440-d_{002}\right) /(0.3440-0.3354) \times 100 \%
$$

The degree of graphitization also can be characterized through the intensity ratio of the D to $\mathrm{G}$ bands $\left(I_{D} / I_{G}\right)$ in Raman spectroscopy (Renishaw in Via Reflex system at an excitation wavelength of $445 \mathrm{~nm}$ ). Besides, the relationship between $L_{a}$ and $I_{D} / I_{G}$ could be presented by the empirical formula proposed by Tuinstra and Koening (T-K) (7) [27].

$$
L a=C(\lambda) /\left(I_{D} / I_{G}\right)
$$

Where $C(\lambda)=2.085 \mathrm{~nm}$ is a fitting constant.

Morphologies of graphite anode were observed under SEM (JEOL/S4800) and TEM (JEOL /JEM2100) to further investigate its microstructure.

Electrical resistivity of graphite anode (perpendicular to the molding direction) at room temperature was measured by DC four-probe method.

\section{Results}

\subsection{QM calculations}

Figure 1 shows the representative structures which were identified, constructed, and optimized to afford ground-state structures. These structures were selected so that a 
rigorous quantum chemical description would exist while still limiting the structures as simple as possible electronic arrangement. Hydrocarbon frameworks were used instead of all-carbon frameworks to clearly define the lowest energy spin state of the system.
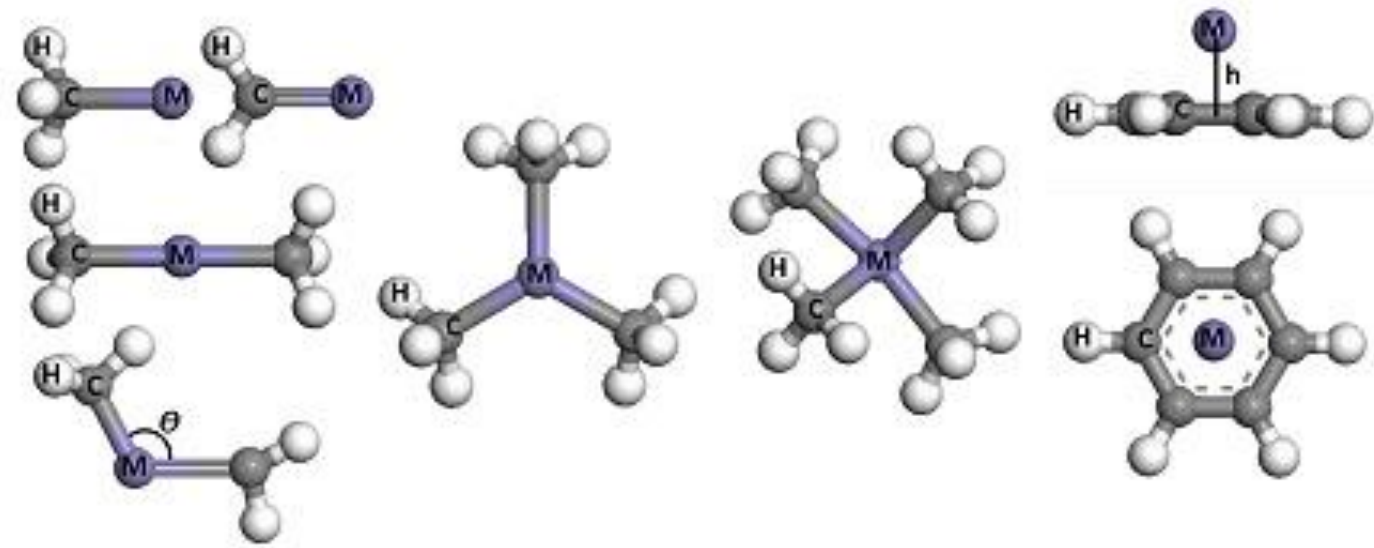

$$
\begin{gathered}
\mathrm{H}_{3} \mathrm{C}-\mathrm{M} \longrightarrow \mathrm{H}_{3} \mathrm{C} \cdots \cdots \cdots \cdot \mathrm{M} \\
\mathrm{M}=\mathrm{CH}_{2} \longrightarrow \mathrm{M}: \cdots \cdots \cdot \mathrm{CH}_{2} \\
\mathrm{AM} \longrightarrow \mathrm{M}
\end{gathered}
$$

Figure 1 Representative structures and their dissociation pathways (M stands for metal atom).

Figure 2 shows the key bond dissociation energy determined by calculating the energy of the reactants and reaction products. From Figure 2, it is observed that our research results agree well with the results in the reference [21]. All the dissociation energy of $\mathrm{Co}$ and $\mathrm{Cu}$ demonstrate that the method and parameters are reasonable. To form the ring, double bond would be essential, and Fe exhibits greater binding energy than $\mathrm{Ti}$ ( $\sim 93.6$ and $\sim 83.4 \mathrm{kcal} / \mathrm{mol}$, respectively). The dissociation energy of $\mathrm{Ti}$ coordinating the secondary, tertiary, and fourth carbon are very similar $(\sim 63.4,64.0$, and $61.8 \mathrm{kcal} / \mathrm{mol}$, respectively), which is also observed in La and Pr cases. For the Pr case, the binding energy of the coordination of double bonded carbon is the greatest. No 
obvious changes can be observed in all binding stations of metal atom with benzene ring; however, the exception is the strong bond between $\mathrm{Ce}$ and benzene ring $(\sim 11.2$ $\mathrm{kcal} / \mathrm{mol})$.

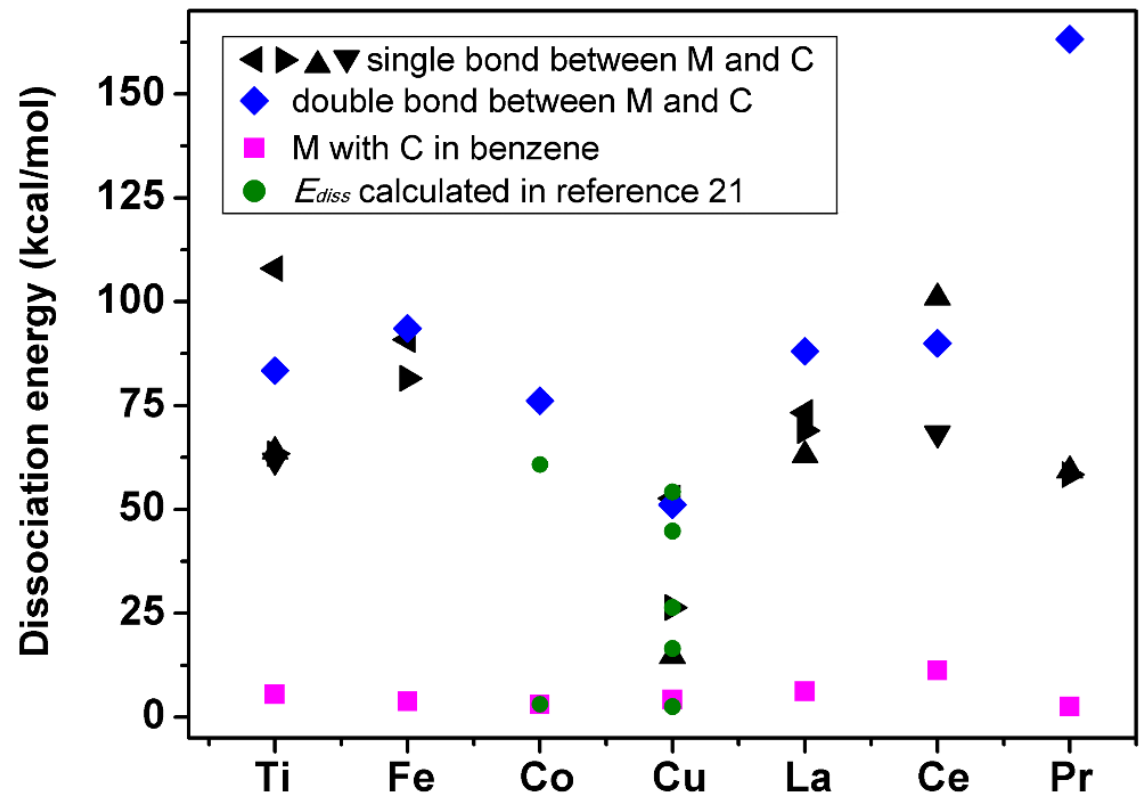

Figure 2 Differences of bond dissociation energy among several metals with carbon.

(Black triangles $\Delta \nabla$ represent the dissociation energy of metal atom coordinating the single, secondary, tertiary, and fourth carbon; blue rhombus represents the dissociation energy of double bond between metal and carbon; purple square represents the dissociation energy of metal atom and benzene ring; and green circular represents the dissociation energy calculated in the reference [21].)

\subsection{XRD and Raman analysis}

Figure 3 shows XRD patterns (a) and Raman spectra (b) of graphite anode with and without $\operatorname{Pr}_{6} \mathrm{O}_{11}$. The intensity of (002) peak decreases with the addition of $\operatorname{Pr}_{6} \mathrm{O}_{11}$, however, the exception in this trend is observed in GA-Pr1.0 case, where the intensity of (002) peak increases exceptionally. 
In Raman spectra, graphite exhibits three main peaks at around 1350, 1580, and $2735 \mathrm{~cm}^{-1}$, and the spectrum baseline was almost plain [29, 30]. The G-band (1580 $\mathrm{cm}^{-1}$ ), which is assigned to the "in-plane" displacement of carbons strongly coupled in the hexagonal sheets, demonstrates a slight shift to higher frequency with the $\operatorname{Pr}_{6} \mathrm{O}_{11}$ additive, and the peak becomes sharp. The peak at D-band $\left(1350 \mathrm{~cm}^{-1}\right)$ is absent in the single crystal graphite, corresponding to the defect-induced Raman band. Another defects band at $2735 \mathrm{~cm}^{-1}$, known as the $\mathrm{G}^{\prime}$-band, arises as a result of the different interlayer interactions that occur at different depths within graphite layers.

(a)

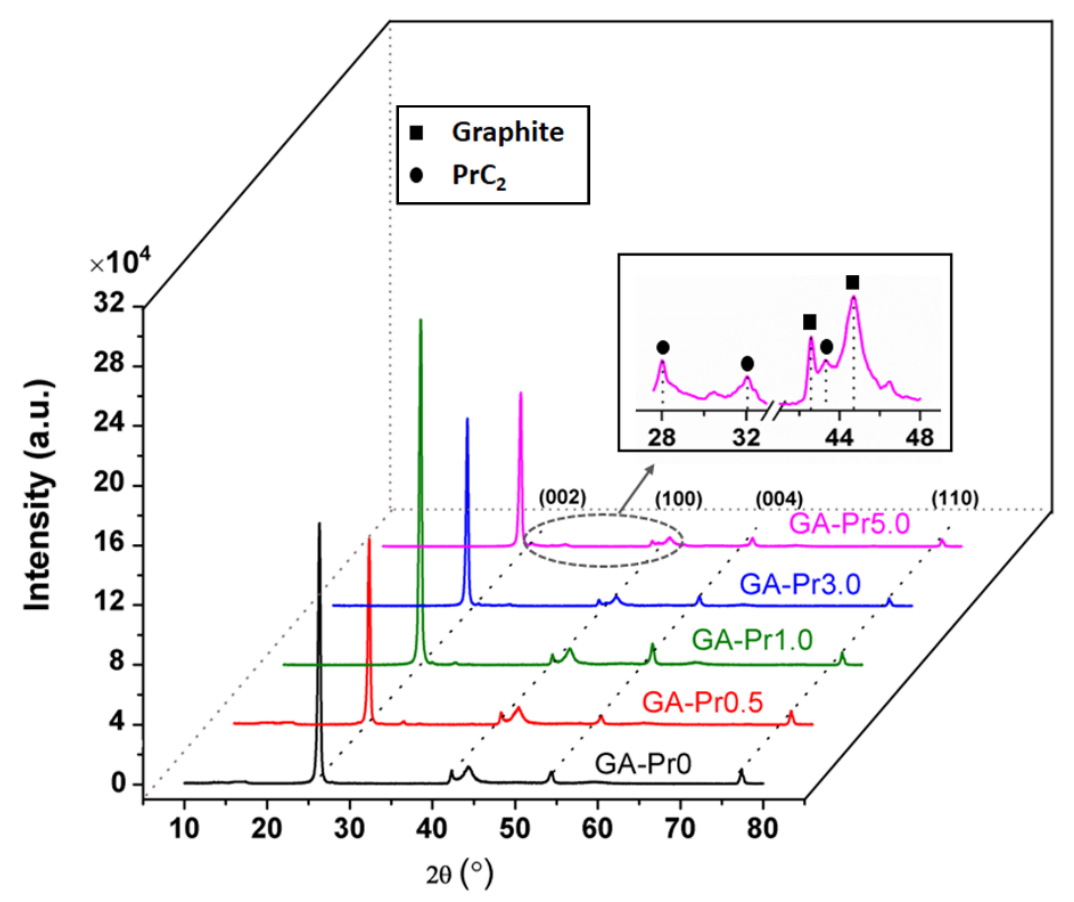


(b)

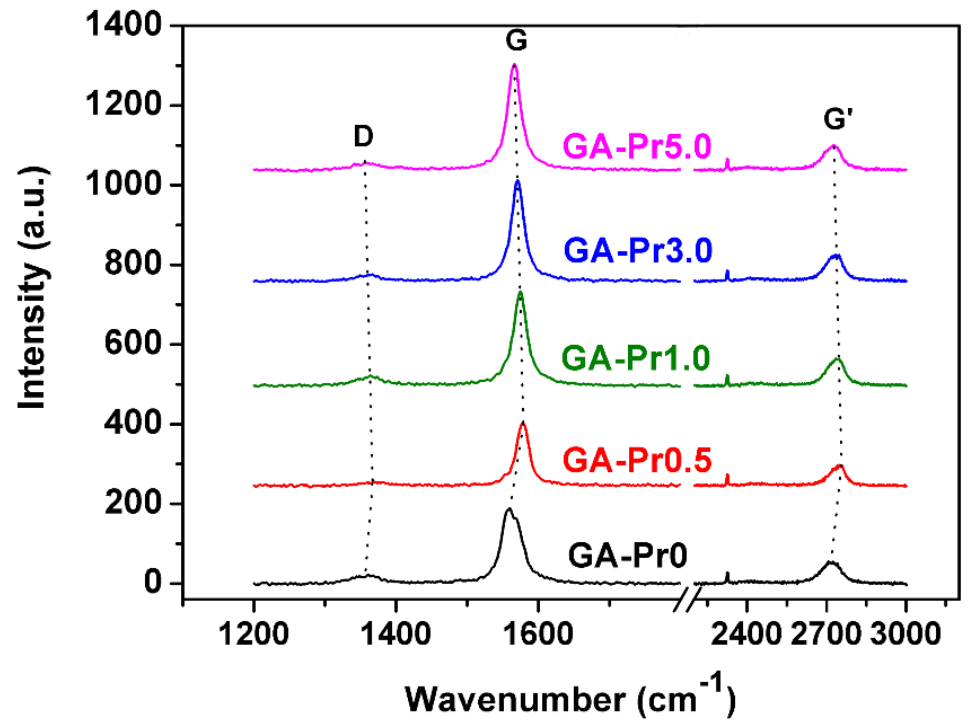

Figure 3 XRD patterns (a) and Raman spectra (b) of graphitized samples with and without $\operatorname{Pr}_{6} \mathrm{O}_{11}$

Figure 4(a) shows the effect of $\operatorname{Pr}_{6} \mathrm{O}_{11}$ content on interlayer spacing $\left(d_{002}\right)$ and $g$ in the graphite anode. The different effect of the selected additives with the same amount 1 wt. $\%$ on $d_{002}$ and $g$ value, reveals their different catalytic ability as shown in Figure 4(b). The $d_{002}$ value of GA-Pr0 is $0.3366 \mathrm{~nm}$, whereas it decreases to $0.3358 \mathrm{~nm}$ (GA-Pr1.0), which is very close to $0.3354 \mathrm{~nm}$ for the hexagonal graphite. The $g$ value of GA-Pr1.0 is $95.06 \%$, which is higher than ones of the samples added with other metals.

(a)

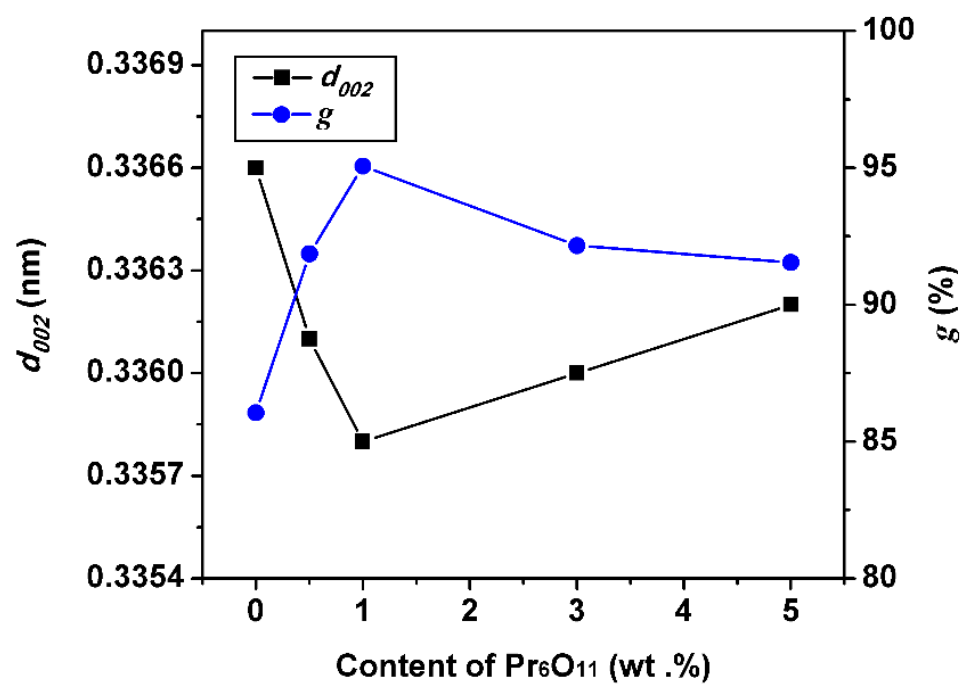


(b)

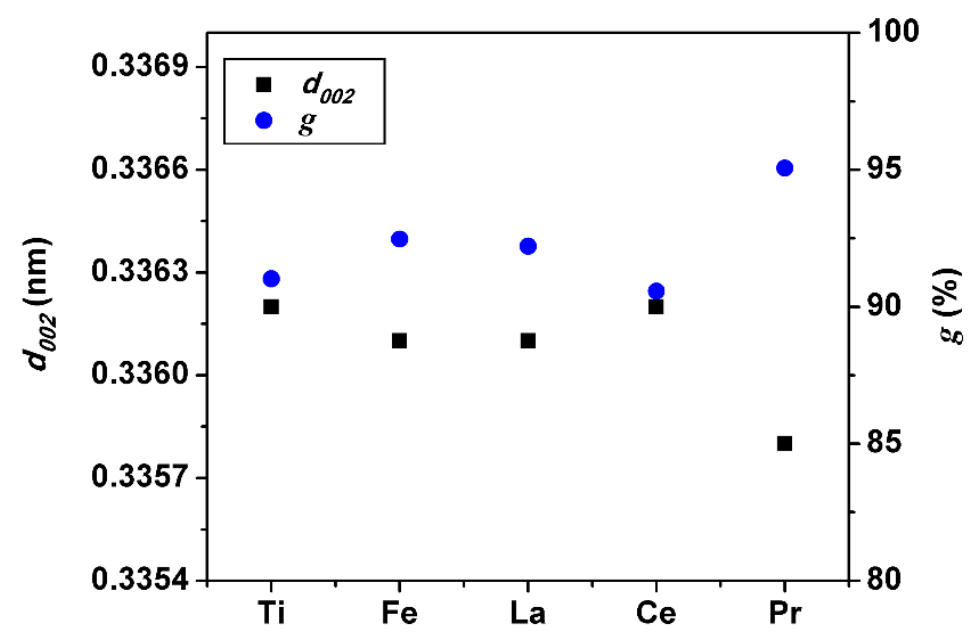

Figure 4 (a) Effect of $\operatorname{Pr}_{6} \mathrm{O}_{11}$ adding content on $d_{002}$ and $g$; (b) Effect of different additives on $d_{002}$ and $g$ in the graphite anodes.

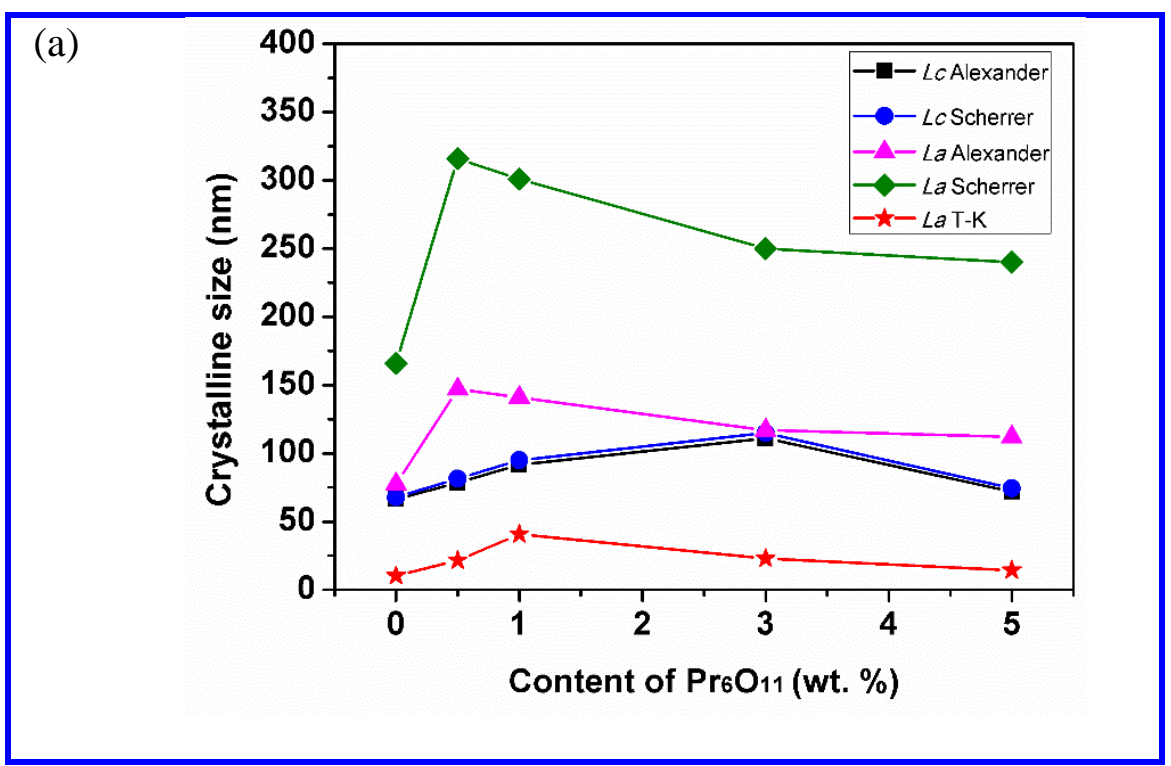




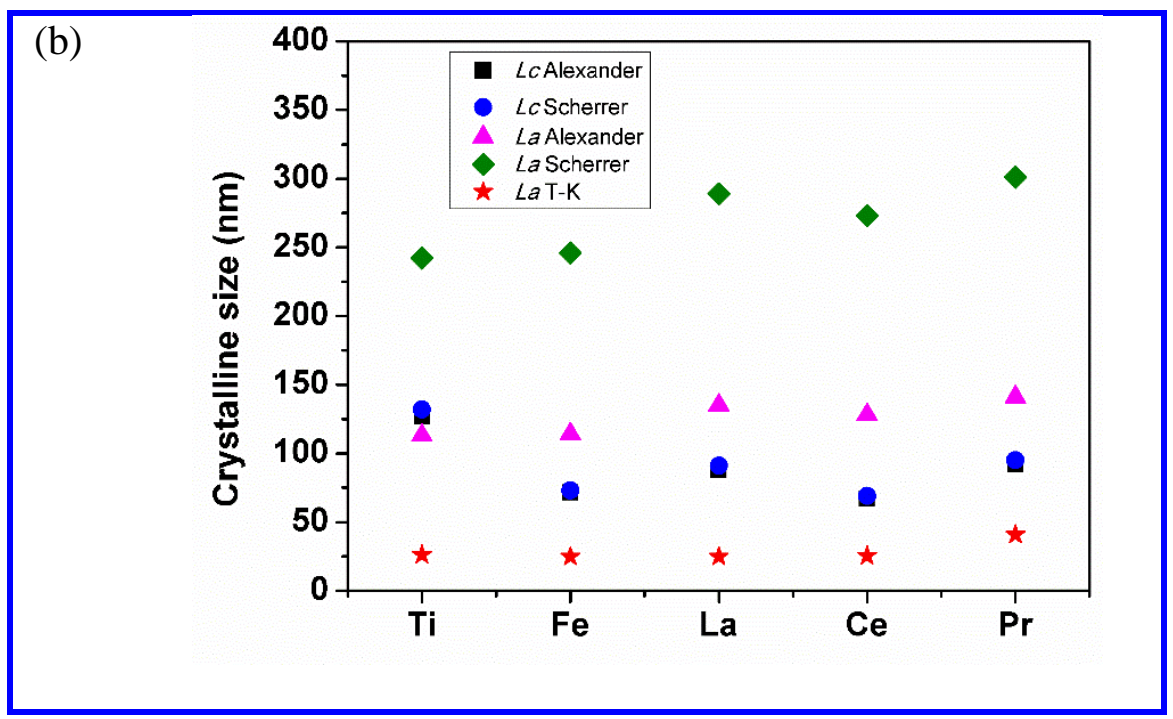

Figure 5 (a) Effect of $\operatorname{Pr}_{6} \mathrm{O}_{11}$ adding content on crystalline size; (b) Effect of different additives on crystalline size in the graphite anodes.

Figure 5(a) shows the effect of $\operatorname{Pr}_{6} \mathrm{O}_{11}$ content on crystalline size, and Figure 5(b) shows the effect of different additives on crystalline size in the graphite anode. As known, the smaller the $I_{D}$, the better the extent of graphitization [15, 31, 32]. Sample GA-Pr1.0 provides the lowest $I_{D} / I_{G}$ ratio $(0.051)$, whereas GA-Pr0 and GA-Pr5.0 do much higher ratios of 0.202 and 0.145 , respectively. The tendency of $I_{D} / I_{G}$ is contrary to the trend of $L_{a}$ calculated from T-K formula. Both $L_{c}$ and $L_{a}$ increase with additive in all cases. No matter in what case, the trends in two calculation expressions proposed by Scherrer or Alexander are similar, and their difference is just due to the shape factor $K$. The $L_{a}$ values of graphite anodes derived from XRD pattern are several times larger than those from Raman spectra.

\subsection{Morphologies of graphite anodes with and without $\operatorname{Pr}_{6} O_{11}$}

Figures 6 and 7 show SEM and TEM images of graphite anode. Compared with GA-Pr0, GA-Pr1.0 exhibits the larger flake graphite. However, this enlargement effect appears to weaken when the adding content of $\operatorname{Pr}_{6} \mathrm{O}_{11}$ is increase up to $5 \mathrm{wt}$. \% 

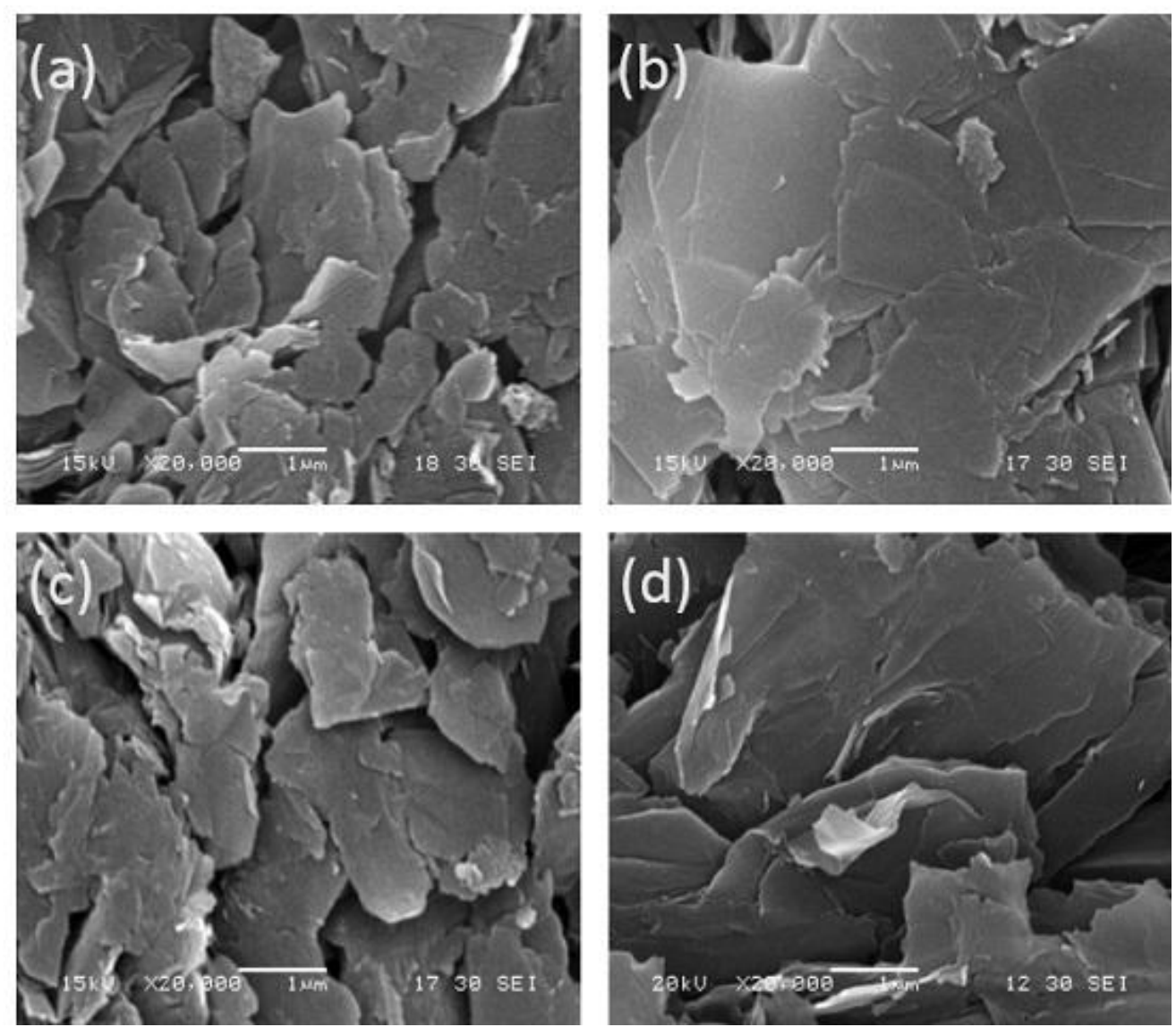

Figure 6 SEM photographs of samles graphitized at $2800{ }^{\circ} \mathrm{C}$ :(a) sample without $\operatorname{Pr}_{6} \mathrm{O}_{11}$,

(b) sample with 1 wt. $\% \operatorname{Pr}_{6} \mathrm{O}_{11}$, (c) sample with 5 wt. $\% \operatorname{Pr}_{6} \mathrm{O}_{11}$; and (d) sample without $\mathrm{Pr}_{6} \mathrm{O}_{11}$ graphitized at $3000{ }^{\circ} \mathrm{C}$. 

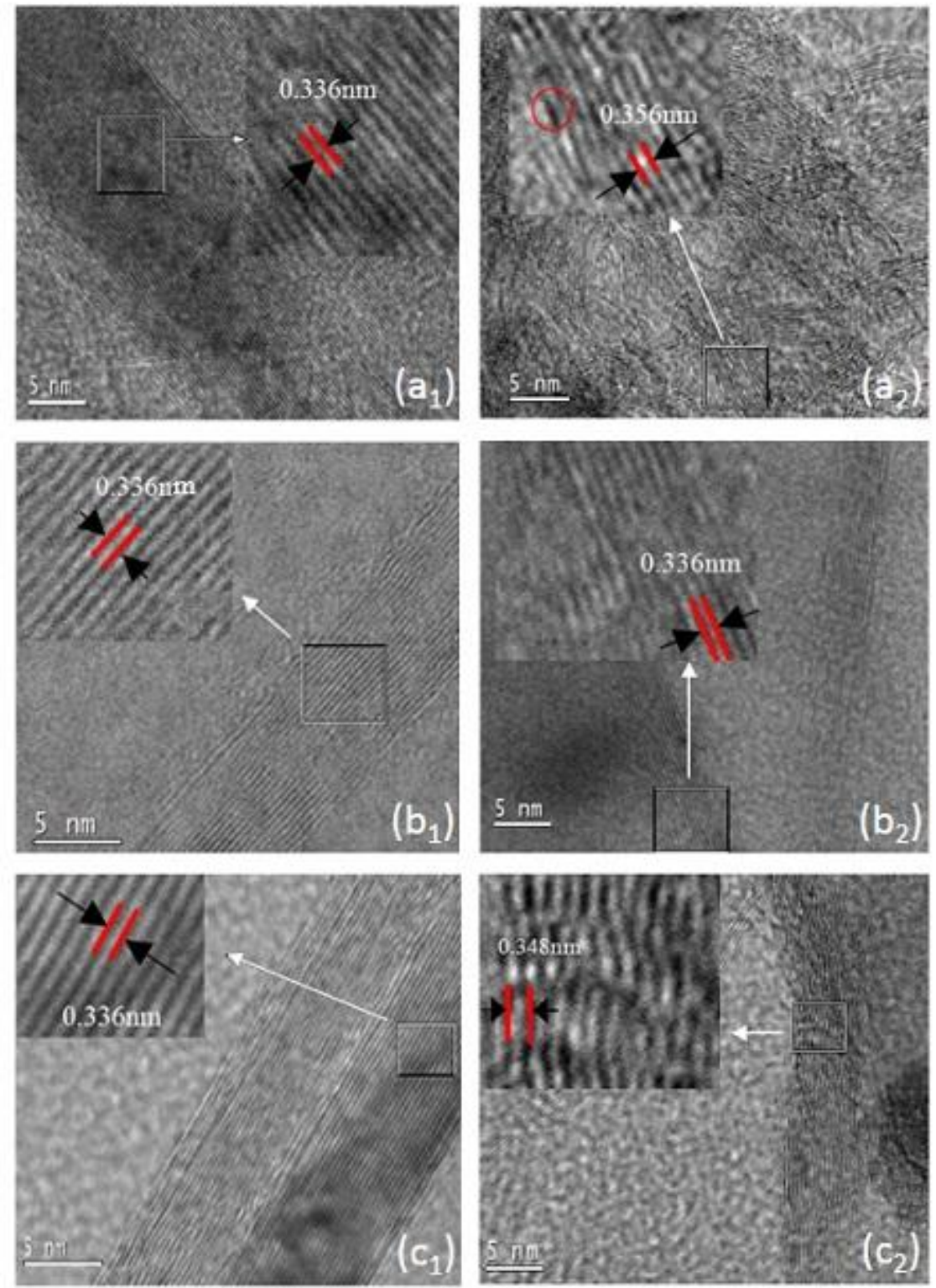

Figure 7 TEM photographs of samples graphitized at $2800^{\circ} \mathrm{C}$ : (a) sample without $\operatorname{Pr}_{6} \mathrm{O}_{11}$, (b) sample with 1 wt. $\% \operatorname{Pr}_{6} \mathrm{O}_{11}$; and (c) sample without $\operatorname{Pr}_{6} \mathrm{O}_{11}$ graphitized at $3000{ }^{\circ} \mathrm{C}$.

Perfect layer structures $\left(d_{002}=0.336 \mathrm{~nm}\right)$ and turbostratic structures $\left(d_{002}=0.356\right.$ $\mathrm{nm}$ ) were both observed in sample GA-Pr0, probably because of the following: in graphite anode, there are three types of precursors: needle coke, and cokes derived from binder and impregnation pitch. The needle coke is easy to be graphitized at higher temperature than $2000{ }^{\circ} \mathrm{C}$. The binder pitch packs the needle coke during the mixing, 
and the impregnation pitch fills the voids at the re-baking stage. Both cokes derived from these pitches are slightly difficult to be graphitized. Therefore, the observed images of GA-Pr0 in high magnification are the combination of the graphitized and less graphitized carbons. However, the less graphitized layer structures of graphite nearly disappear in GA-Pr1.0.

\subsection{Bulk density and electrical resistivity of graphite anodes}

(a)

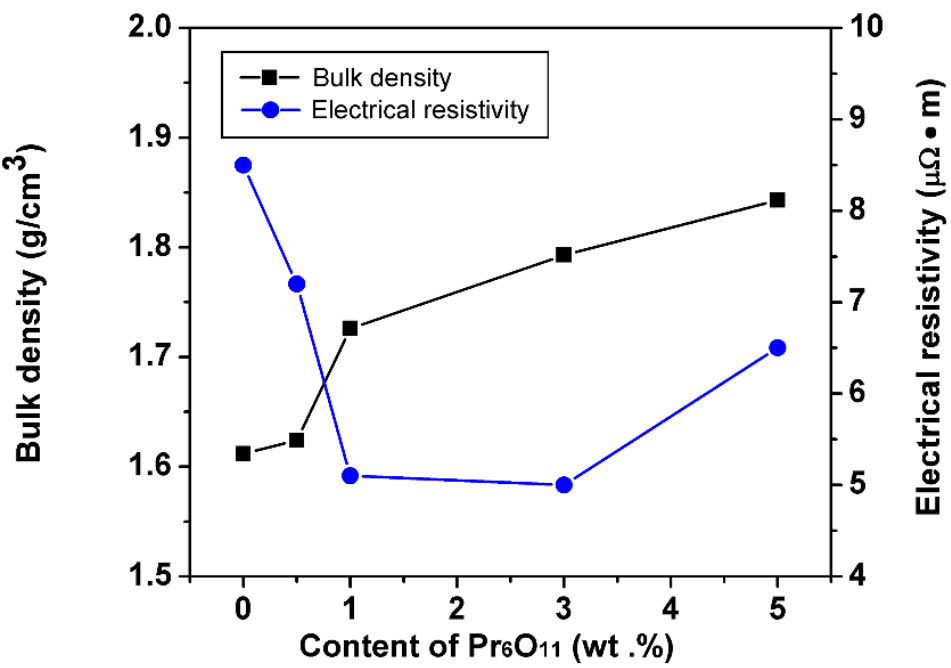

(b)

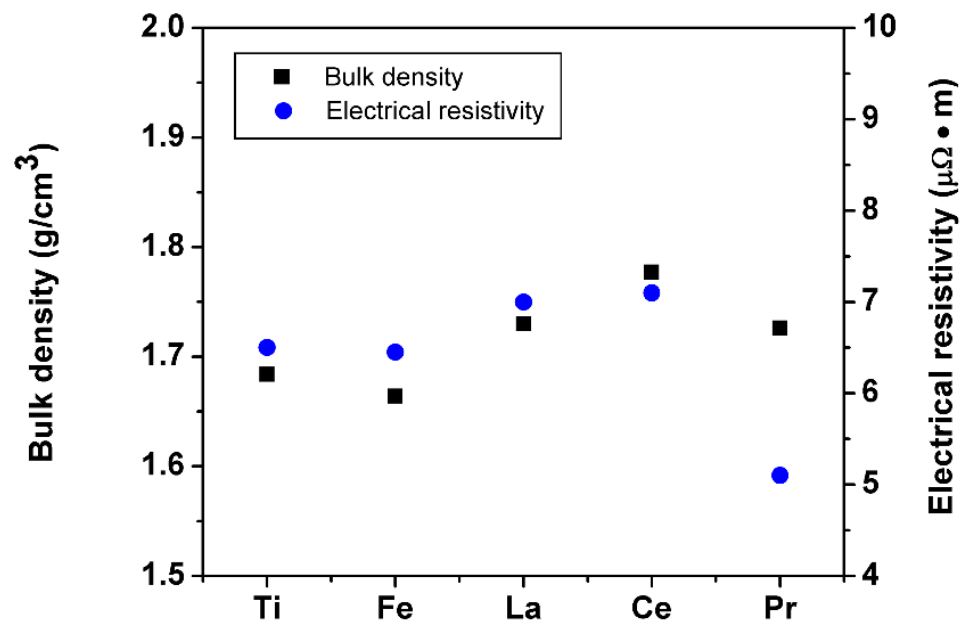

Figure 8 (a) Effect of $\operatorname{Pr}_{6} \mathrm{O}_{11}$ adding content on bulk density and electrical resistivity;

(b) Effect of different additives on bulk density and electrical resistivity in the graphite anodes. 
Figure 8 shows the bulk density and electrical resistivity of graphite anodes. The bulk density of the samples increases with additive in all cases. The graphite anodes with $\operatorname{Pr}_{6} \mathrm{O}_{11}$ additive exhibit the bulk density increases with increasing $\operatorname{Pr}_{6} \mathrm{O}_{11}$ content. The electrical resistivity of the graphite anodes decreases with increasing $\operatorname{Pr}_{6} \mathrm{O}_{11}$ content when it is less than $3 \mathrm{wt}$ \% , and then increases with further increase of $\operatorname{Pr}_{6} \mathrm{O}_{11}$ content. No significant difference of bulk density was observed among these graphite anodes with different additives. Similar effect on electrical resistivity was observed with additives except for $\operatorname{Pr}_{6} \mathrm{O}_{11}$. The highest bulk density of $1.843 \mathrm{~g} / \mathrm{cm}^{3}$ was obtained in GA-Pr5.0 and the lowest electrical resistivity of $5.0 \mu \Omega \cdot \mathrm{m}$ was observed in GA-Pr3.0.

\section{Discussion}

\subsection{Selection of efficient catalyst by QM calculation}

The catalytic ability among several metals is different. The interaction between metal and carbon is very important to characterize not only a metal's ability to form single bind with one, two, and three carbons, but also the double bond between metal and carbon. The reason is that they occur very frequently during the carbonization and graphitization. Specially, the behavior of doubly bound carbon is important because of the role it plays in ring formation, of key interest in many catalysis problems [21]. After the formation of stable small ring, a metal atom stays in two sites: as part of benzyne complex or around the benzene ring. The former is concerned with the rate that a catalyst can enter or leave the defective ring. The latter strongly relates to the departure of catalyst for further catalyzing other places where it will be needed. It is worth pointing out that the dissociation of a metal from six-membered aromatic ring has referential value, as in benzene, with a dissociation path parallel to the axis of the $\pi$ 
system. Based on these, representative structures in Figure 1 were identified to investigate the differences of catalytic abilities among metals.

The comparative study is in accordance with the definition of dissociation energy. Higher dissociation energy can predict the stronger combination between metal and carbon atoms, whereas lower dissociation energy results in metal atom escaping from the benzene ring, favoring highly stable rings, thus extending the graphitic sheets. In fact, bond dissociation energy between metal and carbon atoms were extensively used to calibrate the force field in molecular dynamics simulation by calculating more accurate DFT value $[19,21,22]$. These force fields were confirmed to be applied in the simulation of catalytic formation of carbon nanotubes and the investigation of graphitization ability of transition metals for catalysis of carbon nanotubes by chemical vapor deposition $[21,33]$. It is reasonable to believe that the bond dissociation energy could be used to assess the metal's catalytic ability.

Firstly, $\mathrm{Co}$ and $\mathrm{Cu}$ were chosen to detect the reasonability of parameters based on the existing data of them in the reference [21]. The typical metals to be selected for the DFT calculation represent three kinds of transition metals due to their different electronic structures. For instance, Ti represents those metals whose $d$ shell possess 2 5 electrons while Fe and Co do those $d$ shell possessing 6 10 ones. Based on considering, the calculations were performed by combining with the extensive research of $\mathrm{Fe}$ and $\mathrm{Ti}[2,6,10,34]$. Similarly, for rare-earth cases, three light rare-earth elements $\mathrm{La}, \mathrm{Ce}$, and Pr were chosen due to the differences of the $f$ shell among them.

Both Fe and Ti readily form multiple bonds $(\geq 2)$ necessary for creating new C-C bonds, indicating that they are likely active and may help the quick formation of small ring. Both Fe and Ti dissociate readily from benzene rings $(\sim 3.81$ and $\sim 5.48 \mathrm{kcal} / \mathrm{mol}$, 
respectively), allowing them to catalyze the formation of highly stable rings and subsequently depart for further catalysis. It is further confirmed that the difference in the dissociation energy by calculating the simple structure between metal and carbon atoms is effective in estimating the metal's catalytic ability. Although the catalytic effects of $\mathrm{Fe}$ and $\mathrm{Ti}$ are good, their amount used in carbon materials is a limiting factor (even $\geq 10$ wt. \%) $[6,10]$. Ce coordinates benzene ring strongly, causing its residue and becoming obstruction during the catalytic process. The energy of the binding of Pr with benzene ring was the lowest, allowing the recycling of Pr atom for further catalysis. For the reason, $\operatorname{Pr}$ was focused on, and then $\operatorname{Pr}_{6} \mathrm{O}_{11}$ was selected to be catalyst, through considering its chemical affinity for sulfur and nitrogen as puffing inhibitor during catalytic graphitization [35].

\subsection{Effect of $\operatorname{Pr}_{6} \mathrm{O}_{11}$ on the microstructure and electrical property of graphite anodes}

Compared with sample GA-Pr0, all the graphite anodes prepared with $\operatorname{Pr}_{6} \mathrm{O}_{11}$ additive possess lower $d_{002}$ and larger $L_{c}$ values. As expected, the $L_{c}$ value displays a trend that is analogous to $d_{002}$ value [36]. $\operatorname{Pr}_{6} \mathrm{O}_{11}$ additive promotes the micro-crystallinity $[11,37]$. A high content $(>3 \mathrm{wt} . \%)$ of the catalyst results in the localized graphitization in the sample, thus increasing the crystallite boundaries, decreasing both $L_{c}$ and $L_{a}$ values, and subsequently diminishing the flake graphite. This restraint on the development of layer structures with further increase of additive was proved by both XRD data and SEM images. Therefore, an optimal amount of the $\operatorname{Pr}_{6} \mathrm{O}_{11}$ additive is required. For instance, the addition of $\operatorname{Pr}_{6} \mathrm{O}_{11}$ with 1 wt. $\%$ in mixture exhibited better catalytic activity, and was more effective for enhancing the degree of graphitization and the $L_{a}$ value, whereas 3 wt. $\% \operatorname{Pr}_{6} \mathrm{O}_{11}$ in mixture, was more effective for enhancing the $L_{c}$ value. Besides, it indicated that graphitic order extends farther in 
the direction of the planes than perpendicular to them because of the observation that $L_{a}$ values are systematically higher than $L_{c}$ values [36].

The results of Raman spectra demonstrate a good agreement with XRD data, and the degree of graphitization increases with $\operatorname{Pr}_{6} \mathrm{O}_{11}$ adding content. The samples with $\sim 1$ wt. $\% \operatorname{Pr}_{6} \mathrm{O}_{11}$ in mixture exhibited the highest degree of graphitization, indicating that an optimal amount of $\operatorname{Pr}_{6} \mathrm{O}_{11}$ additive is required.

The $L_{a}$ value increases with the increasing content of $\operatorname{Pr}_{6} \mathrm{O}_{11}$ at the early stage but then gradually decreases. The values is about $100 \mathrm{~nm}$ calculated from the (110) peak followed by the expression used in the standard method, which is consistent with the observation in the references $[26,36]$. Here, the $L_{a}$ values derived from XRD pattern are four times larger than those from Raman spectra. This agrees with the results reported by Käärik et al., who studied the porous carbon derived from $\mathrm{SiC}$ with catalyst, and observed the same problems of $L_{a}$ values calculated from (100) peak [27]. Besides, Badenhorst found that Raman technique suffers from the limitation for crystallinity estimates when it is used below an $I_{D} / I_{G}$ ratio of 0.1 [28]. However, both tendency of $L_{a}$ values from XRD and Raman techniques are similar, so that the difference of the values does not influence the assessment of graphite anode with the increase amount of $\operatorname{Pr}_{6} \mathrm{O}_{11}$.

The value of electrical resistivity varies significantly for different graphitized carbon materials, and is positively related to the degree of graphitization, thickness of graphite crystalline, and bulk density [38]. Compared with sample GA-Pr1.0, GA-Pr3.0 provides larger $L_{c}$ and higher bulk density, which may be the main reason for the decrease in electrical resistivity. In terms of their effects on electrical resistivity, $L_{c}$ is the most important, followed by bulk density and degree of graphitization. With further increase of $\operatorname{Pr}_{6} \mathrm{O}_{11}$ content, the $L_{c}$ and degree of graphitization decrease and electrical resistivity increases. Here, $\operatorname{Pr}_{6} \mathrm{O}_{11}$ plays the roles as catalyst as well as impurity, thus 
probably restraints the extension of direction of graphitic planes, and subsequently increases the electrical resistivity.

To better understand the effect of $\operatorname{Pr}_{6} \mathrm{O}_{11}$ on graphitization, the sample without additive was treated at $3000{ }^{\circ} \mathrm{C}$ and labeled as sample GA-Pr0'. Compared with sample GA-Pr0, GA-Pr0’ possesses a smaller interlayer spacing $(0.3363 \mathrm{~nm})$, larger crystalline size $\left(L_{c}=68.6 \mathrm{~nm}\right.$ and $L_{a}=125 \mathrm{~nm}$ from formula of Alexander, respectively), and lower electrical resistivity $(7.8 \mu \Omega \cdot \mathrm{m})$. The structures of graphite anode after $3000{ }^{\circ} \mathrm{C}$ HTT are more ordered than those at $2800{ }^{\circ} \mathrm{C}$. However, there are curved lamellar structure to be observed in GA-Pr0' but not in GA-Pr1.0, indicating that $\operatorname{Pr}_{6} \mathrm{O}_{11}$ not only assisted the formation of layer structures, but also corrected the carbon atom to stand in a regular line (Figure $7\left(b_{2}\right)$ and $\left.\left(c_{2}\right)\right)$. Therefore, it is reasonable to consider that it is difficult to produce perfect graphitized samples just by increasing the graphitization temperature without additive. Moreover, $\operatorname{Pr}_{6} \mathrm{O}_{11}$ significantly favors the graphitization of graphite anode, supported by the fact that the performance of GA-Pr1.0 on microstructure and electrical property are better than GA-Pr0', or even at a lower temperature.

\subsection{Comparison of $\mathrm{Pr}_{6} \mathrm{O}_{11}$ and other typical catalysts}

Since the catalytic ability of $\operatorname{Pr}_{6} \mathrm{O}_{11}$ has come to our attention that $\mathrm{Yi}$ et al. reported the degree of graphitization of furan resin is significantly improved with 15 wt. \% praseodymium nitrate $\left(d_{002}=0.3360 \mathrm{~nm}\right.$ and $\left.L_{c}=26 \mathrm{~nm}\right)$ [32]. The effect of praseodymium nitrate started to play its role when added in furan resin at $4 \mathrm{wt}$. \%. In this case that the non-graphitizable carbon was treated at $2400{ }^{\circ} \mathrm{C}$ in the reference [32], and more content of catalyst is responsible for developing high degree of graphitization. Other rare-earth elements also exhibited the good catalytic ability. Both yttrium nitrate 
and lanthanum oxide as additives provided good catalytic effects when they were added (about 4-5 wt. \%) into carbon materials [14-15]. As XRD patterns shown, similar parabolic-kind tendency was observed in these references $[14,15,32]$.

However, the above comparison appears not to be appropriate because of their different raw materials and preparation procedure, thus several metal catalysts with the same adding amount in graphite anodes were carried out. The $g$ and $I_{D} / I_{G}$ of graphite anodes exhibited the similar trends, indicating that the effect of all the other metal catalysts almost identical when they were added in graphite anodes with 1 wt. \%.

When the additive is used in carbon materials, the possible changes of $L_{c}$ value included (1) increase with increasing content of additive, and finally reaching a plateau or appearing opposite effect; (2) increase with additive but no variation by content of additive $[14,39]$. Ti was proved to follow the latter, thus it could be explained that GA-Ti1.0 gives the largest $L_{c}$ value in this study. As discussion in Section 4.2, $L_{a}$ values are generally larger than $L_{c}$ ones, however, GA-Ti1.0 exhibits the different situation $-L_{c}$ is slightly higher than $L_{a}$. The $L_{a}$ derived from (110) peak in all the rare-earth cases are larger than those in the other transition metal cases. However, the $L_{a}$ derived from T-K formula demonstrates the viewpoint that the catalytic graphitization only weakly influences the $L_{a}$ value of the crystalline proposed by Käärik [27]. Maybe the $L_{a}$ values calculated from XRD patterns obviously demonstrate the more ordered parts due to the catalysts. Therefore, it is reasonable that the catalytic effect of additive in carbon materials on microstructures of carbon materials could be assessed by combining with $d_{002}$, degree of graphitization, $I_{D} / I_{G}$, and crystalline size. From the above analysis, GA-Pr1.0 possesses the lowest $d_{002}$ and $I_{D} / I_{G}$, highest degree of graphitization, and greatest crystalline size. Besides, GA-Pr1.0 also exhibits the lowest electrical resistivity $(5.11 \mu \Omega \cdot \mathrm{m})$, when compared with the other samples added by 
other catalysts with the same amount additive of $1 \mathrm{wt} . \%$.

Compared with the other additives, $\operatorname{Pr}$ can more efficiently improve the degree of graphitization, enlarge the crystalline size, and decrease the electrical resistivity of the graphite anode. These experimental results are in accordance with calculation results, predicting that it is meaningful and worth further discussion to select the efficient catalyst by DFT calculation.

\subsection{Catalytic mechanism of rare-earth elements}

At present, three mechanisms were proposed to explain the catalytic graphitization of carbon substrates $[2,40]$. The first is the disordered carbon dissolution into the catalyst and subsequent precipitation as graphite, which is the pathway of the group VIII metals (Fe, Co, Ni) catalyzing the graphitization according to this mechanism. The second mechanism is the carbide formation by the reaction of carbon with metal catalyst and subsequent decomposition to produce graphite. Silicon catalyst follows this mechanism [41, 42]. The third is the dissolution-precipitation sequence that occurs by the carbide formation. Many researchers reported that titanium reacts readily with carbon to form carbide following the third mechanism [7, 34].

The exact mechanism involved in catalytic graphitization is obscure. The XRD patterns (zoomed of curves in Figure 3(a)), clearly demonstrate that a-PrC $\mathrm{C}_{2}$ really exists in the graphitized sample. Therefore, combined with the Pr-C binary phase diagram, the following explanation may be more reasonable. After being added into carbon substrate, $\operatorname{Pr}_{6} \mathrm{O}_{11}$ reacts with active carbon to form a-PrC $\mathrm{C}_{2}$ at temperatures higher than $1600{ }^{\circ} \mathrm{C}$. Then, a-PrC $\mathrm{C}_{2}$ decomposes to form free praseodymium and graphitic structures. Here, the active carbon includes the disordered carbon and low-ordered graphite microcrystalline (unstable graphite) structure. The free carbon will tend to occupy the 
low energy site around the stable graphite crystal. As the active carbon has higher internal energy, it easily reacts with praseodymium to form praseodymium carbide. In the process, the stable graphite crystals grow larger, and the disordered carbon and unstable graphite crystals diminish.

$\operatorname{Pr}_{6} \mathrm{O}_{11}$ can accelerate the graphitization from the turbostratic structures into the ordered layer ones (Figure $7\left(a_{2}\right)$ and $\left(b_{2}\right)$ ). There are two ways to transform the turbostratic structures into ordered ones: adjusting the layer structures in the same orientation and re-assembling the carbon atom into the order of graphite layer structures. However, the re-orientation of the layer structures is difficult, because of the existence of solid position resistance. Therefore, re-assembling the atom into the order of graphite layer structures at high temperatures is the reasonable path. The results of this study are in agreement with the phenomenon that turbostratic structures disappear at $3000{ }^{\circ} \mathrm{C}$, being close to the station of the graphite sublimation temperature, and the carbon atom with high thermal energy in microcrystalline state can move one by one. For the high bond energy among carbon atoms, the escape of carbon atom from the less-ordered carbon materials is much more difficult. In the presence of $\operatorname{PrC}_{2}$, the activation energy is apparently lower, and the reaction rate is much higher. From above, $\operatorname{Pr}_{6} \mathrm{O}_{11}$ can be proved to effectively catalyze the graphitization of carbon materials.

Similar carbides $\left(\mathrm{LaC}_{2}\right.$ and $\left.\mathrm{CeC}_{2}\right)$ were observed in XRD patterns (shown in Supplementary Figure S2), suggesting that they followed the same process with Pr. The catalytic mechanism involves the formation of free carbon through formation and decomposition of carbide. The interpretations of rare-earth catalytic mechanism is followed in equations (8-11).

$$
\begin{aligned}
& C+R E_{m} O_{n} \longrightarrow \alpha R E C_{2} \\
& \alpha R E C_{2} \longrightarrow R E(g)+C^{*}
\end{aligned}
$$




$$
\begin{gathered}
(\text { graphite })_{N}+C^{*} \longrightarrow(\text { graphite })_{N} \cdots C \longrightarrow(\text { graphite })_{N+1} \\
R E+\text { disordered-carbon }+ \text { unstable-graphite } \longrightarrow \alpha R E C_{2}
\end{gathered}
$$

where $R E_{m} O_{n}$ is rare-earth oxide, $\mathrm{C}^{*}$ is free carbon, (graphite) $)_{\mathrm{N}}$ is graphite crystal including $\mathrm{N}$ carbon atoms, (graphite) ${ }_{\mathrm{N}+1}$ is graphite crystal including $\mathrm{N}+1$ carbon atoms, and (graphite) $)_{\mathrm{N}} \cdots \mathrm{C}$ is graphitization transition state. However, the catalytic graphitization mechanism still further needs to be investigated in depth by both the calculation and experiment.

\section{Conclusion}

The dissociation energy of different bonding forms between some metals and carbon atoms was calculated by the aid of DFT method, and an efficient catalyst $\left(\operatorname{Pr}_{6} \mathrm{O}_{11}\right)$ was successfully selected to catalyze the graphitization of carbon materials. $\operatorname{Pr}_{6} \mathrm{O}_{11}$ was found to be a new additive to catalyze the graphitization in carbon materials, and proved the best catalyst among the selected additives according to the experimental results. $\operatorname{Pr}_{6} \mathrm{O}_{11}$ with a low amount of only 1 wt. \% in the graphite anode was found to be more effective to enhance the degree of graphitization. The lowest electrical resistivity of $5.0 \mu \Omega \cdot \mathrm{m}$ was obtained when 3 wt. $\% \operatorname{Pr}_{6} \mathrm{O}_{11}$ was added in graphite anode. Finally, based on these experimental results, the catalytic mechanism of rare-earth elements was proposed involved the formation of graphitic carbon through the formation and decomposition of rare-earth carbide.

\section{Acknowledgements}

This work was supported by National Science Foundation of China (U1407202) and the Fundamental Research Funds for the Central Universities.

\section{References}


[1] Rubenstein J, Davis B. Wear testing of inert anodes for magnesium electrolyzers. Metall and Materi Trans B 2007; 38(2):193-201.

[2] Ōya A, Marsh H. Phenomena of catalytic graphitization. J Mater Sci 1982; 17(2):309-22.

[3] Maldonado-Hodar FJ, Moreno-Castilla C, Rivera-Utrilla J, Hanzawa Y, Yamada Y. Catalytic graphitization of carbon aerogels by transition metals. Langmuir 2000; 16(9):4367-73.

[4] Murty HN, Biederman DL, Heintz EA. Bulk catalysis of graphitization. 3. Effect of boron. Fuel 1977; 56(3):305-12.

[5] Liu T, Luo RY, Yoon S-H, Mochida I. Anode performance of boron-doped graphites prepared from shot and sponge cokes. J Power Sources 2010; 195(6):1714-9. [6] Murty HN, Biederman DL, Heintz EA. Bulk catalysis of graphitization. 4. Effect of titanium. Fuel 1978; 57(7):442-6.

[7] Qiu HP, Song YZ, Liu L, Zhai GT, Shi JL. Thermal conductivity and microstructure of Ti-doped graphite. Carbon 2003; 41(5):973-8.

[8] Yi SJ, Wu C, Fan Z, Kuang YF, Chen JH. Catalytic graphitization of PAN-based carbon fibers by spontaneously deposited manganese oxides. Transit Metal Chem 2009; 34(5):559-63.

[9] Liu YC, Liu QL, Gu JJ, Kang DM, Zhou FY, Zhang W, et al. Highly porous graphitic materials prepared by catalytic graphitization. Carbon 2013; 64:132-40.

[10]Xu SH, Zhang FY, Kang Q, Liu SH, Cai QY. The effect of magnetic field on the catalytic graphitization of phenolic resin in the presence of $\mathrm{Fe}-\mathrm{Ni}$. Carbon 2009; 47(14):3233-7.

[11]Zhai DY, Du HD, Li BH, Zhu YA, Kang FY. Porous graphitic carbons prepared by combining chemical activation with catalytic graphitization. Carbon 2011; 
49(2):725-9.

[12]Aikawa S, Kizu T, Nishikawa E. Catalytic graphitization of an amorphous carbon film under focused electron beam irradiation due to the presence of sputtered nickel metal particles. Carbon 2010; 48(10):2997-9.

[13] Gao XQ, Liu L, Guo QG, Shi JL, Zhai GT. The effect of zirconium addition on the microstructure and properties of chopped carbon fiber/carbon composites. Compos Sci and Technol 2007; 67(3-4):525-9.

[14] Yi SJ, Fan Z, Wu C, Chen JH. Catalytic graphitization of furan resin carbon by yttrium. Carbon 2008; 46(2):378-80.

[15]Zhang C, Lu GM, Sun Z, Yu JG. Catalytic graphitization of carbon/carbon composites by lanthanum oxide. J Rare Earth 2012; 30(2):128-32.

[16]Bugnet M, Kula A, Niewczas M, Botton GA. Segregation and clustering of solutes at grain boundaries in Mg-rare earth solid solutions. Acta Mater 2014; 79(0):66-73.

[17] Strout DL, Hall MB. Small yttrium-carbon and lanthanum-carbon clusters: rings are most stable. J Phys Chem 1996; 100(46):18007-9.

[18]Ticknor BW, Bandyopadhyay B, Duncan MA. Photodissociation of noble metal-doped carbon clusters. J Phys Chem A 2008; 112(48):12355-66.

[19] Shibuta Y, Maruyama S. Bond-order potential for transition metal carbide cluster for the growth simulation of a single-walled carbon nanotube. Comp Mater Sci 2007; 39(4):842-8.

[20]Jensen BD, Bandyopadhyay A, Wise KE, Odegard GM. Parametric study of ReaxFF simulation parameters for molecular dynamics modeling of reactive carbon gases. J Chem Theory Comput 2012; 8(9):3003-8.

[21]Nielson KD, van Duin ACT, Oxgaard J, Deng W-Q, Goddard WA. Development of the ReaxFF reactive force field for describing transition metal catalyzed reactions, with 
application to the initial stages of the catalytic formation of carbon nanotubes. J Phys Chem A 2005; 109(3):493-9.

[22] Meinander A, Henriksson KOE, Björkas C, Vörtler K, Nordlund K. The effect of C concentration on radiation damage in Fe-Cr-C alloys. J Nucl Mater 2013; 442(1-3, Supplement 1):S782-S5.

[23]Qi TT, Bauschlicher CW, Lawson JW, Desai TG, Reed EJ. Comparison of ReaxFF, DFTB, and DFT for phenolic pyrolysis. 1. Molecular dynamics simulations. J Phys Chem A 2013; 117(44):11115-25.

[24]Becke AD. Density - functional thermochemistry. III. The role of exact exchange. J Chem Phys 1993; 98(7):5648-52.

[25]Miehlich B, Savin A, Stoll H, Preuss H. Results obtained with the correlation energy density functionals of becke and Lee, Yang and Parr. Chem Phys Lett 1989; 157(3):200-6.

[26]Iwashita N, Park CR, Fujimoto H, Shiraishi M, Inagaki M. Specification for a standard procedure of X-ray diffraction measurements on carbon materials. Carbon 2004; 42(4):701-14.

[27] Käärik M, Arulepp M, Karelson M, Leis J. The effect of graphitization catalyst on the structure and porosity of SiC derived carbons. Carbon 2008; 46(12):1579-87.

[28]Badenhorst H. Microstructure of natural graphite flakes revealed by oxidation: Limitations of XRD and Raman techniques for crystallinity estimates. Carbon 2014; 66:674-90.

[29] Jawhari T, Roid A, Casado J. Raman spectroscopic characterization of some commercially available carbon black materials. Carbon 1995; 33(11):1561-5.

[30]Ferrari AC. Raman spectroscopy of graphene and graphite: Disorder, electron-phonon coupling, doping and nonadiabatic effects. Solid State Commun 2007; 
143(1-2):47-57.

[31]Tzeng S-S. Catalytic graphitization of electroless Ni-P coated PAN-based carbon fibers. Carbon 2006; 44(10):1986-93.

[32] Yi SJ, Chen JH, Xiao X, Liu L, Fan Z. Effect of praseodymium on catalytic graphitization of furan resin carbon. J Rare Earth 2010; 28(1):69-71.

[33]Shibuta Y, Elliott J A. A molecular dynamics study of the graphitization ability of transition metals for catalysis of carbon nanotube growth via chemical vapor deposition. Chem Phys Lett 2009; 472(4-6):200-6.

[34]Lin QY, Feng ZH, Liu ZJ, Guo QG, Hu ZJ, He LL, et al. Atomic scale investigations of catalyst and catalytic graphitization in a silicon and titanium doped graphite. Carbon 2015; 88:252-61.

[35]Fujimoto K-I, Mochida I, Todo Y, Oyama T, Yamashita R, Marsh H. Mechanism of puffing and the role of puffing inhibitors in the graphitization of electrodes from needle cokes. Carbon 1989; 27(6):909-17.

[36] Vázquez-Santos MB, Geissler E, László K, Rouzaud J-N, Martínez-Alonso A, Tascón JMD. Comparative XRD, Raman, and TEM study on graphitization of PBO-derived carbon fibers. J Phys Chem C 2012; 116(1):257-68.

[37] Zhai DY, Li BH, Kang FY, Du HD, Xu CJ. Preparation of mesophase-pitch-based activated carbons for electric double layer capacitors with high energy density. Micropor Mesopor Mat 2010; 130(1-3):224-8.

[38] Adams PM, Katzman HA, Rellick GS, Stupian GW. Characterization of high thermal conductivity carbon fibers and a self-reinforced graphite panel. Carbon 1998; $36(3): 233-45$.

[39] He DM, Zhang FY, Xu SH, Yu WX, Cai QY, T. J. LaTempa et al. Synergistic catalytic effect of Ti-B on the graphitization of polyacrylonitrile-based carbon fibers. 
Carbon 2008; 46(11):1506-8.

[40] Ōya A, Ōtani S. Influences of particle size of metal on catalytic graphitization of non-graphitizing carbons. Carbon 1981; 19(5):391-400.

[41] Qiu HP, Han L, Liu L. Properties and microstructure of graphitised ZrC/C or SiC/C composites. Carbon 2005; 43(5):1021-5.

[42] Niu YA, Zhang X, Wu J, Zhao JP, Yan XQ, Li Y. Catalytic and enhanced effects of silicon carbide nanoparticles on carbonization and graphitization of polyimide films. Rsc Adv 2014; 4(80):42569-76. 